\title{
Kala - ympäristövastuu monimutkaisessa kentässä
}

\author{
Frans Silvenius ${ }^{1)}$, Timo Mäkinen ${ }^{2)}$, Juha Grönroos ${ }^{3)}$, Sirpa Kurppa ${ }^{1)}$, Raija Tahvonen ${ }^{1)}$ Mar- \\ kus Kankainen $^{2)}$, Jouni Vielma ${ }^{2)}$, Kirsi Silvennoinen ${ }^{1)}$, Jari Setälä ${ }^{2)}$, Salla Kaustell ${ }^{1)} \&$ Hanna \\ Hartikainen $^{1)}$ \\ ${ }^{1)}$ MTT Maa- ja elintarviketalouden tutkimuskeskus, Biotekniikka- ja Elintarviketutkimus Kestävä \\ biotalous, Latokartanonkaari 9,00790 Helsinki, etunimi.sukunimi@mtt.fi \\ ${ }^{2)}$ RKTL Riista-ja kalatalouden tutkimuslaitos, Viikinkaari 4, PL 2, 00790 Helsinki, etuni- \\ mi.sukunimi@rktl.fi \\ ${ }^{3)}$ SYKE Suomen ympäristökeskus, PL 140, 00251 Helsinki, etunimi.sukunimi@ymparisto.fi
}

\section{Tiivistelmä}

Suomessa kasvatetun kirjolohen pääasialliset ympäristövaikutukset tutkittiin Maa- ja elintarviketalouden tutkimuskeskuksen, Riista- ja kalatalouden tutkimuslaitoksen ja Suomen ympäristökeskuksen tekemässä yhteistyöhankkeessa 2009-2012. Tutkimus suoritettiin elinkaariarviointimenetelmällä ja tutkitut kvantitatiivisesti lasketut ympäristövaikutusluokat olivat rehevöityminen, ilmastonmuutos ja happamoituminen.

Tutkimuksen pääasiallinen tavoite oli päivittää kymmenen vuoden takaiset tutkimustulokset (Seppälä ym. 2001). Tutkimustarve tiedostettiin, koska ennakolta tiedettiin kalankasvatuksen rehevöittävän kuormitusten pienentyneen johtuen rehun käyttömäärien pienentymisestä suhteessa kasvatettuun kalamäärään sekä rehujen kehityksestä. Saaristomeren ja Ahvenanmeren kalankasvatus poistettiin Suomen ympäristöministeriön vaatimuksesta Itämeren pahimpien ympäristökuormittajien niin kutsutulta hotspot-listalta Itämeren suojelukomission Helcomin 18.-19.11.2002 Tukholmassa pidetyssä kokouksessa.

Tutkimuksen tavoitteena oli myös osoittaa kirjolohen kasvatuksen kehittämismahdollisuudet, vertaamalla erilaisten tuotantomenetelmien ympäristövaikutuksia. Kirjolohen kasvatuksen elinkaarisia ympäristövaikutuksia verrattiin myös ravitsemuksen kannalta muiden vaihtoehtoisten tuotteiden ympäristövaikutuksiin. Tässä vertailussa erityistä huomiota kiinnitettiin tuotteiden erilaiseen ravintosisältöön, nimenomaan kirjolohen sisältämiin arvokkaisiin omega3-rasvahappoihin

Elinkaariarvioinnissa huomioitiin kasvatetun kirjolohen tuotejärjestelmän toiminnot sisältäen rehun tuotantoketjuun kuuluvien alkutuotannon panostuotannon, raaka-aineiden viljely- sekä kalastusprosessin, rehun valmistusprosessin, poikaslaitoksen toiminnot, kasvatustoiminnat, erilaisten raakaaineiden sekä rehun kuljetukset, pakkausten valmistuksen sekä kalan fileoinnin. Vertailtavien lihatuotteiden rajaukset tehtiin yhteneväisiksi ja siten vertailukelpoisiksi kirjolohen kanssa.

Tärkein havainto oli se, että rehevöittävät päästöt olivat suhteessa tuotettuun kalamäärään vähentyneet vuosina 2002-2009 $26 \%$ johtuen sekä rehujen että ruokintatekniikan kehittymisestä. Elinkeinon absoluuttiset päästöt olivat pienentyneet noin $10 \%$. Muiden muutosten arviointi on vielä kesken, mutta rehun kulutusmäärä suhteessa kasvatettuun kalamäärään (rehukerroin) oli pienentynyt noin $10 \%$, mikä vaikuttaa hiilijalanjälkeen, happamoitumiseen ja primaarienergian kulutukseen.

Hiilijalanjäljeksi saatiin fileetonnia kohti 4060 kg CO2-ekv/t ja rehevöittäviksi päästöiksi 38,6 $\mathrm{kg}$ PO4-ekv/t.

Huomattava mahdollisuus vähentää kirjolohen kasvatuksen rehevöittäviin päästöihin havaitiin olevan tutkimustulosten mukaan Itämeren kalan käyttäminen kirjolohen ravintona. Tällöin ravinteita poistuisi Itämerestä kalastuksen mukana enemmän kuin mitä kirjolohen kasvatuksessa päätyy vesistöön.

Asiasanat: LCA, hiilijalanjälki, rehevöityminen, kirjolohi, Itämeri, luonnonkala 


\section{Johdanto}

Tutkimuksen taustana oli päivitystarve Suomen ympäristökeskuksen, Riista- ja kalatalouden tutkimuslaitoksen, ja Suomen Kalankasvattajaliiton vuosina 1999-2001 tekemälle elinkaariarvioinnille koskien keskimääräistä Suomessa tuotettua kasvatettua kirjolohta (Seppälä ym. 2001). Päivitystarve huomattiin Maa- ja elintarviketalouden tutkimuskeskuksessa vuosina 2007-2009 tehdyssä laajassa tutkimuksessa, jossa kartoitettiin erilaisten lounaslautasten elinkaarisia ympäristövaikutuksia (Saarinen ym. 2011). Aiemmassa tutkimuksessa tehtiin osittain karkeiksi jääneitä vertailuita suomalaisesta kirjolohesta norjalaiseen kasvatettuun loheen, Suomessa kalastettuun silakkaan sekä Suomessa tuotettuun sian- ja naudanlihaan. Nyt uusien tutkimustietojen valossa havaittiin, että laskelmia sekä kirjolohen kasvatuksesta että vertailtavista tuotteista pystyttäisiin suorittamaan huomattavan paljon luotettavammalla pohjalla kuin vanhan tutkimuksen suorittamisen aikoihin. Lisäksi tiedettiin, että kirjolohen kasvatuksen rehevöittävät kuormitukset olivat pienentyneet tällä aikavälillä huomattavasti (Kuva 1.).

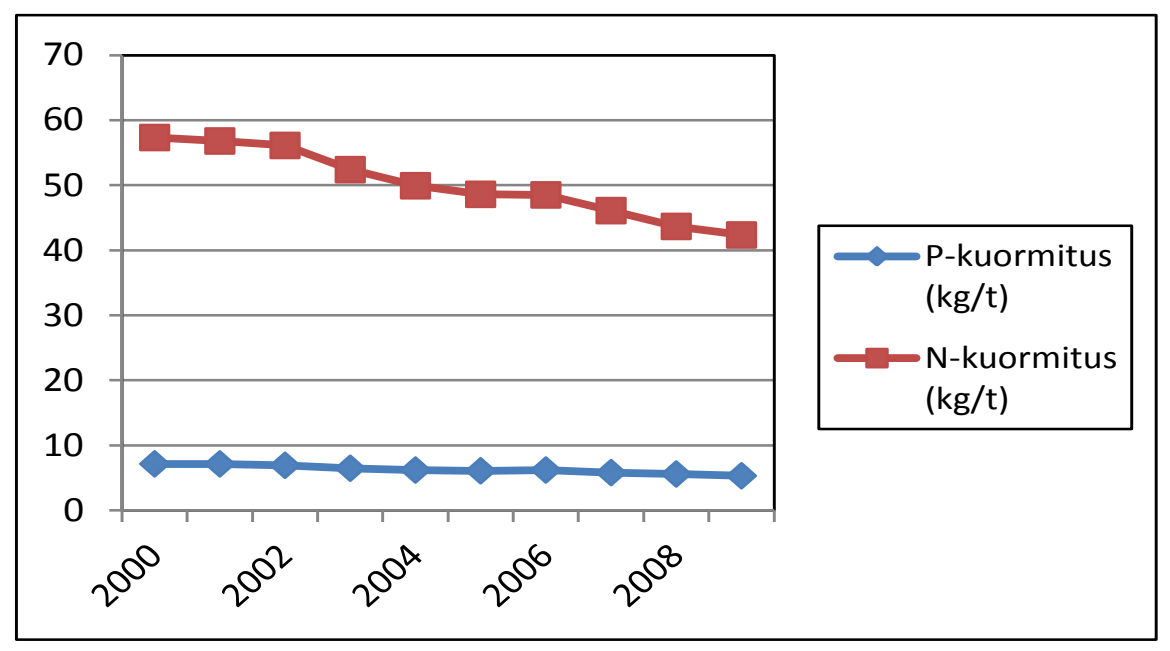

Kuva 3. Kalankasvatuksen ravinnekuormituksen kehittyminen 2000-2009 (Kallioniemi 2009, 2010).

Kalankasvatustoiminnan seurauksena veteen menevä typpikuormitus oli vuonna 2005 Suomen Ympäristökeskuksen tilastojen mukaan $0,9 \%$ ja fosforikuormitus noin 2,1\% Suomen kokonaiskuormituksista ja Saaristomeren ja Ahvenanmeren kalankasvatus poistettiin Suomen ympäristöministeriön vaatimuksesta Itämeren pahimpien ympäristökuormittajien niin kutsutulta hotspot-listalta Itämeren suojelukomission Helcomin 18.-19.11.2002 Tukholmassa pidetyssä kokouksessa. Tutkimuksessa tarkasteltavan päätuotteen, eli kotimaassa kasvatetun kirjolohen osalta pääasiallinen muutos ennakoitiin olevan rehun kulutuksen pienenemisessä tuotantokiloa kohden sekä sen ominaisuuksien muutoksissa siten, että kalankasvatuksen ominaiskuormitus on pienentynyt.

Kala on erittäin tärkeä osa terveellistä ravitsemusta nimenomaan arvokkaiden rasvahappojensa ansiosta. Suomalaisissa ravitsemussuosituksissa kalaa suositellaan syötäväksi $2-3$ kertaa viikossa. Kun keskimääräinen kirjolohiannos on noin 150 g, tulee viikkoannokseksi 300 - 450 g. Kuluttajien ympäristövastuun kannalta on välttämätöntä, että luonnonkalan ja kasvatetun kalan samoin kuin eri kalalajien keskinäinen paremmuus suhteessa ympäristökuormitukseen voidaan ilmoittaa. Ravitsemukseen suhteutetun ympäristövaikutustarkastelun kannalta kalaa tulee voida verrata myös muihin rinnasteisiin proteiinilähteisiin; kasviperäisistä palkokasviravintoon ja eläinperäisistä eri lihalaatuihin.

\section{Aineisto ja menetelmät}

Tutkimuksessa selvitettiin kasvatetun kirjolohen ja siihen vertailtavien elintarviketuotteiden tuotannosta aiheutuvat kasvihuonekaasupäästöt (hiilijalanjälki), rehevöittävät ja happamoitta- 
vat päästöt, alailmakehän otsonin muodostumiseen vaikuttavat päästöt sekä primaarienergian kulutus. Päästöjen merkittävyys ympäristövaikutusten kannalta määriteltiin käyttämällä yleisesti käytössä olevia karakterisointikertoimia, joiden avulla kyseiset päästöt saatiin muunnettua vaikutusluokittain yhteismitallisiksi (Solomon ym. 2007 Seppälä ym. 2004 Seppälä ym. 2006). Suomalaisen kalankasvatuksen osalta rehevöittävät päästöt mallinnettiin käyttämällä suomalaisiin olosuhteisiin sopivia kulkeutumis- ja vaikutuskertoimia (Seppälä ym. 2004). Lisäksi arvioitiin kvantitatiivisesti kalankasvatuksessa käytettävien antibioottien määrä sekä ekotoksikologisena tekijänä verkkokasseissa käytetyn antifouling-materiaalin ympäristövaikutukset.

Tutkimuksen toiminnallinen yksikkö oli $1000 \mathrm{~kg}$ nahatonta kirjolohifileetä jalostamon portilla. Järjestelmänrajauksiin sisältyivät kaikki kasvatetun kirjolohen tuotejärjestelmän toiminnot alkaen rehun tuotantoketjuun kuuluvien alkutuotannon panostuotannosta ja edelleen rehun tuotantoprosessista päätyen kalan fileointiin. Kalan fileointi otettiin mukaan rajauksiin, koska näin pystyttiin tekemään paremmin vertailuita muihin elintarviketuotteisiin vertailuperusteina eläinten ihmisravinnoksi kelpaava osa. Vertailtavien lihatuotteiden rajaukset tehtiin yhteneväiseksi kirjolohen kanssa siten, että myös ne sisälsivät lihatuotteiden osalta alkutuotantoon liittyvän panostuotannon, alkutuotannon, rehun prosessoinnin, eläinten kasvattamisen tilalla ja teurastamon, kun taas luonnonkalatuotteiden rajauksiin kuului kalastuksen polttoaineen kulutus, jäähdytys, perkaus ja fileointi ja kalan kuljetuksissa käytettyjen styrox-laatikoiden tuotanto. Kasvatetun kalan tuotejärjestelmästä arvioitiin karkealla tasolla verkkokassirakenteiden merkitystä. Rakenteiden oletettiin kestävän 20 vuotta. Maatalouskoneiden ja maatilojen muiden rakenteiden sekä tehtaiden ja teiden rakentamista ja ylläpitoa ei huomioitu tutkimuksessa.

Ympäristövaikutusten arviointi tehtiin elinkaariarviointimenetelmällä (Life Cycle Assessment, LCA). Elinkaariarvioinnissa noudatettiin siitä annettuja standardeja ISO 14040 ja ISO 14044. Peruslaskelma tehtiin "Attributional"- eli haitanjako-lähestymistavalla, jossa kohdennetaan ja allokoidaan panoksia ja tuotoksia eri tuotteille. Allokoinnit kalan perkuu ja fileointiprosessissa kohdistettiin pää- ja sivutuotteille niiden taloudelliseen arvon perustuen. Myös soijarouheen ja soijaöljyn välinen allokointi perustui tuotteiden taloudelliseen arvoon. Sen sijaan kalajauhon ja -öljyn välinen allokointi perustui massa-allokointiin. Viljan viljelyn satotähteille, kuten oljille, ei kohdennettu kuormituksia. Allokoinnit teurassivutuotteiden ja lihan välille suoritettiin myös taloudellisiin arvoihin perustuen.

Tutkimuksen tietolähteet nojautuivat suureksi osaksi tilastotietoihin, mikä oli luonnollinen lähestymistapa, koska tutkimuksen tavoitteena oli nimenomaan tutkia keskimääräisiä suomalaisen kirjolohen tuotannon ympäristövaikutuksia. Rehun tuotantoprosessista saatiin tietoja Suomeen rehua toimittavilta rehun valmistajilta sisältäen myös reseptitiedot koskien rehun raaka-aineita. Rehun raakaainekomponenteista soijan tuotannolle käytettiin tietokanta- ja kirjallisuustietoja, kalajauhon- ja öljyn tuotannolle yhden rehunvalmistajan tietoja ja vehnän viljelylle suomalaisia keskimääräisiä tietoja. Kalojen pakkaamiseen käytetyistä styrox-laatikoista saatiin tietoja kolmelta valmistajalta. Fileoinnin tiedot perustuivat yhden jalostajan tietoihin.

\section{Tulokset ja niiden arviointi}

Nahattoman kirjolohifileen hiilijalanjäljeksi saatiin tässä tutkimuksessa 4060 kgCO2-ekv/t (Kuva 2), josta rehun raaka-aineiden tuotannon osuus oli $67 \%$, rehun valmistuksen osuus oli $12 \%$, kasvatustoiminnan $8 \%$, pakkausten $4 \%$, kuljetusten $6 \%$ ja jalostuksen $3 \%$. Kasvatetun kotimaisen kirjolohen hiilijalanjälki oli samaa suuruusluokkaa kuin monissa aiemmissa lohikalojen hiilijalanjälki- ja elinkaariarviointitutkimuksissa (mm. Papatryphon et al. 2004, Winther et al. 2009, Pelletier et al. 2009, http://www.lcafood.dk)

Kirjolohifileen tuotejärjestelmän rehevöittäviksi päästöiksi saatiin tässä tutkimuksessa 38,6 kg $\mathrm{PO}_{4}$-ekvivalenttia suhteessa yhteen tonniin tuotettua kirjolohifileetä, kun leville käyttökelpoisten ravinnekuormitusten määrä on huomioitu (Kuva 3). Kasvatustoiminnan osuus oli $93 \%$ kuormituksista, rehun raaka-aineiden $4 \%$ ja poikaslaitoksen $2 \%$. Kirjolohifileen tuotantoketjun happamoittaviksi päästöiksi saatiin $5,7 \mathrm{~kg}$ AE-ekvivalenttia/t kirjolohifileetä. Tutkittavan tuotejärjestelmän primaarienergiankulutus oli $53133 \mathrm{MJ} / \mathrm{t}$ nahatonta fileetä. 


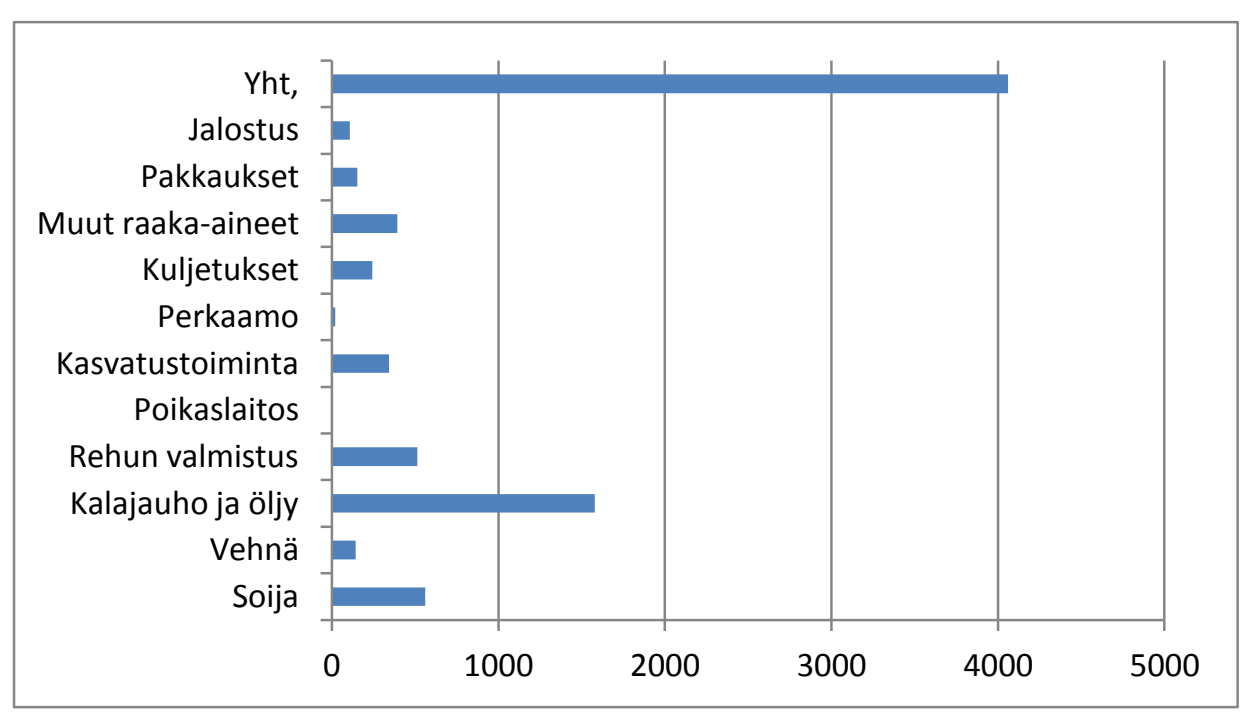

Kuva 2. Suomessa kasvatetun kirjolohen keskimääräinen hiilijalanjälki kgCO2-ekv/t nahatonta kirjolohifilettä.

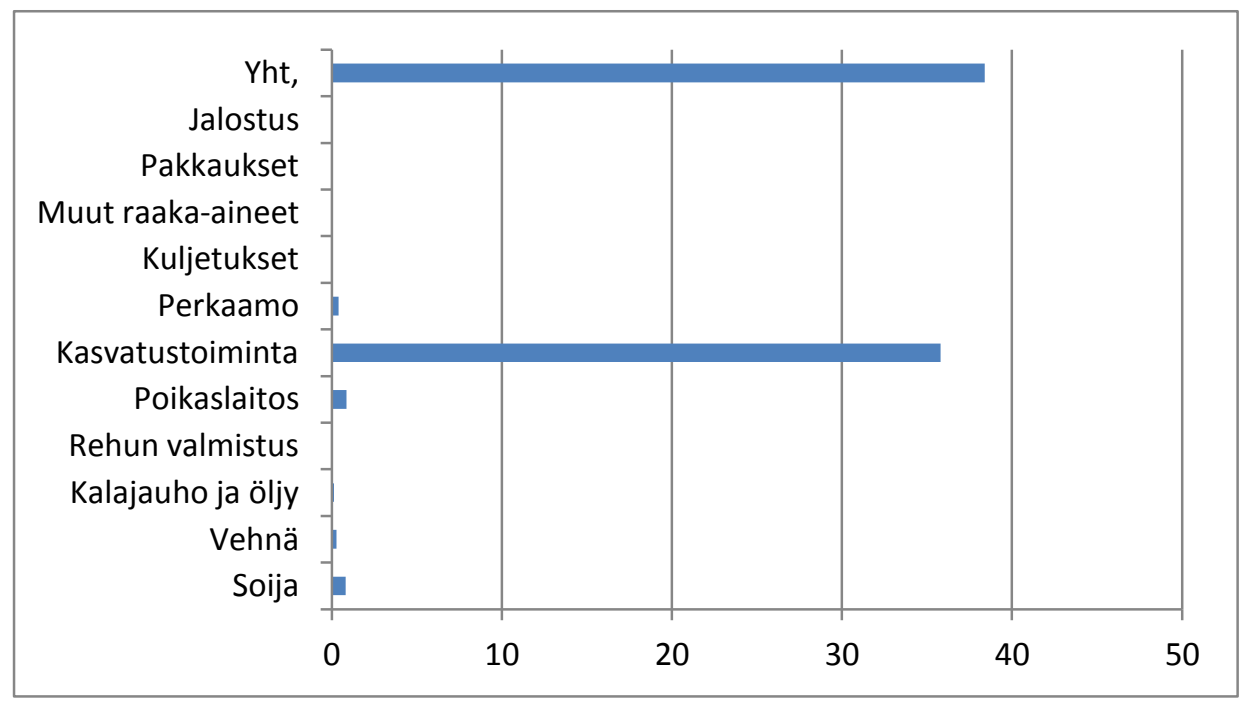

Kuva 3. Suomessa kasvatetun kirjolohen keskimääräiset rehevöittävät päästöt $\mathrm{kgPO}_{4}$-ekv/t nahatonta kirjolohifilettä.

Hankkeessa tehtiin myös vertailua Seppälä ym. (2001) tekemään elinkaariarviointiin kotimaisesta kirjolohesta. Tärkein tulos oli se, että ravinnekuormitus aikavälillä 2002-2009 on pienentynyt suuresti, rehevöittävänä vaikutuksena noin $26 \%$ suhteessa tuotantomäärään (kuva 3). Alustavien tarkasteluiden mukaan hiilijalanjälki oli pienentynyt noin $7 \%$, primaarienergian kulutus yli $20 \%$ ja happamoittavat päästöt noin $28 \%$.

Vertailuja suoritettiin myös luonnonkalaan, joista otettiin laskentaan kuha, siika, ahven ja hauki. Luonnonkalojen pyydystäminen poistaa ravinteita vedestä, jolloin rehevöitymisen suhteen kyseessä on ympäristöhyöty eikä ympäristöhaitta. Kasvatetun kalan hiilijalanjälki oli luonnonkalaa suurempi, koska luonnonkalan tuotantoketjuun ei kuulu rehun tuotantoa. Huomattavaa on kuitenkin, että tässä tutkimuksessa ei tehty herkkyystarkastelua siitä, kuinka erilaiset luonnonkalan kuljetusmatkat, kerralla kuljetettavat määrät ja saalismäärät vaihtelevat.Laskelmissa käytetyt luonnonkalan kuljetusmatkat ja tavat perustuivat asiantuntija-arvioihin.

Huomattava mahdollisuus vähentää kirjolohen kasvatuksen rehevöittäviin päästöihin havaitiin olevan tutkimustulosten mukaan Itämeren kalan käyttäminen kirjolohen ravintona. Tällöin ravinteita poistuisi Itämerestä kalastuksen mukana enemmän kuin mitä kirjolohen kasvatuksessa päätyy vesistöön. Ongelmana on kuitenkin esimerkiksi silakan korkea dioksiinipitoisuus, mutta toisaalta 
nykyään on kehitetty menetelmiä dioksinin poistoon. Lisäksi kasvatetun kirolohen ravinnekuormituksia pystyään vähentämään huomattavasti kiertovesilaitoksella, jolloin taas hiilijalanjälki

Vertailussa kasvatetun kirjolohen ja luonnonkalan välillä on vielä otettava huomioon kalan sisältämät haitalliset aineet. Suuret hauet, ahvenet, mateet ja kuhat sekä eräät tuontikalat saattavat sisältää elohopeaa $0,5-1 \mathrm{mg} / \mathrm{kg}$, jolloin WHO:n saantisuositukset voivat ylittyä, jos kyseistä kalaa syödään 200 grammaa viikossa. Sen sijaan kirjolohen elohopeapitoisuus on pieni (Hallikainen ym. 2010). Eviran suosituksissa kehotetaan raskaana olevia naisia välttämään hauen syöntiä. Merikala sisältää dioksiinia 10 kertaa enemmän kuin Suomessa kasvatettu kala. Myös suomalaisen orgaanisten tinayhdisteiden saanti on suurempi merikaloilla kuin kasvatetulla kalalla (Mankinen 2009). Kirjolohi sisältää noin kertaluokkaa määrän EPA- ja DHA-rasvahappoja verrattuna esimerkiksi haukeen, kuhaan ja ahveneen (http://www.fineli.fi)

Hankkeessa tullaan myös tekemään vertailuita liha- ja kasvituotteiden ympäristövaikutuksiin, joissa otetaan huomioon tuotteiden erilaiset ravintoarvot.

\section{Johtopäätökset}

Kirjolohen kasvatuksen rehevöittävät ominaispäästöt ovat pienentyneet viimeisten kymmenen vuoden aikana selvästi Parhaana mahdollisuutenavähentää kirjolohen kasvatuksen rehevöittäviin päästöihin havaitiin olevan tutkimustulosten mukaan Itämeren kalan käyttäminen kirjolohen ravintona, joka on tulevaisuudessa mahdollista, kun dioksiinia pystytään poistamaan kalaraaka-aineesta. Myös kiertovesilaitos on hyvä menetelmä ravinnepäästöjen vähentämiseen mutta tällöin hiilijalanjälki on korkeampi. Hiilijalanjälki, happamoittavat päästöt ja primaarienergian kulutus ovat myös pienentyneet selvästi.

Kirjolohen ympäristövaikutusten vertailussa muihin elintarvikkeisiin on huomioitava tuotteiden erilainen ravintosisältö. Vaikka esimerkiksi kirjolohen hiilijalanjälki on kalastettua kotimaista kalaa korkeampi, on otettava huomioon kasvatetun kirjolohen pienemmät ympäristömyrkkypitoisuudet ja korkeammat EPA- ja DHA-pitoisuudet kuin kotimaisella luonnonkalalla. Vertailut erilaisiin liha- ja kasvisannoksiin ovat myös haasteellisia ja kyseiset vertailut ovat vielä kesken.

\section{Kirjallisuus}

Hallikainen, A. Rautala T., Ulla Karlström, U., Pirkko Kostamo, P, Pertti Koivisto, P, Raimo Pohjanvirta, R., Veli Hietaniemi, H., Liisa Rajakangas, L., Vesa Tuomaala, V., Harri Kankaanpää, H., Matti Verta, M., Eila Kostiainen, E., Päivi Kurttio, P., Tuukka Turtiainen, T., Hannu Kiviranta, H., Hannu Komulainen, H., Panu Rantakokko, P., Matti Viluksela, V., Esko Niemi, E., Kirsti Nuotio K. \& Kalevi Siivinen, S. 2010. Elintarvikkeiden ja talousveden kemialliset vaarat. Eviran julkaisuja 15/2010.

Elintarvikevirasto 2005. Eviran internetsivut, dioksiinin saanti. http://www.evira.fi/portal/fi/elintarvikkeet/elintarviketietoa/vierasaineet/dioksiinin_saanti

LCA Food Database http://www.lcafood.dk/ 5.10.2011.

Kallioniemi, H. 2009. Lounais-Suomen ympäristökeskus. Kirjallinen tiedonanto 7.8.2009

Kallioniemi, H. 2010. Lounais-Suomen ympäristökeskus Kirjallinen tiedonanto 13.8.2010.

Mankinen K. 2009. Itämeren kalasta ja järvi- sekä tuontikalasta Suomessa 2000-luvulla mitatut organotinapitoisuudet ja niiden saantilaskelmat, Pro Gradu-tutkielma, Helsingin yliopiston ympäristöekologian laitos.

Papatryphon, E., Petit, J., van derWerf, H., 2004. The development of life cycle assessment for the evaluation of rainbow trout farming in France. In: Halberg, N. (Ed.), Life Cycle Assessment in the Agri-Food Sector. Proceedings from the 4th International Conference. Danish Institute of Agricultural Sciences, Horsens, Denmark, pp. 73-80.

Pelletier, N., Tyedmers, P., Sonelsson, U., Scholz, A., Ziegler, F., Flysjo, A., Kruse, S., Cancino, B. \& Silverman, H. 2009. Not All Salmon Are Created Equal: Life Cycle Assessment (LCA) of Global Salmon Farming Systems. Environmental Science \& Technology 2009 43: 8730-8736. 
Saarinen, M., Sirpa Kurppa, S., Ari Nissinen, A. \& Mäkelä, J. (toimittajat) 2011. Aterioiden ja asumisen valinnat kulutuksen ympäristövaikutusten ytimessä. ConsEnv-hankkeen loppuraportti. Suomen ympäristö 14/2011. Helsinki. Ympäristöministeriö, 98s.

Winther, U., Ziegler, F., Hognes, E., Emmanuelsson, A., Sund, V. \& Ellingsen, H. 2009. Carbon footprint and energy use of Norwegian seafood products. SINTEF Fisheries and Aquaculture, Norway. Saatavissa: http://www.sintef.no/upload/Fiskeri_og_havbruk/Internasjonalt_R\%C3\%A5dgivning/2009_Carbon\%20footprint \%20of\%20seafood\%20products.pdf

Seppälä, J., Silvenius, F., Grönroos, J., Mäkinen, T., Silvo, K. \& Storhammar 2008. Kirjolohen tuotanto ja ympäristö. Suomen ympäristö 529. $164 \mathrm{~s}$.

WHO 1990. Environmental Health Criteria 101. Methylmercury, WHO Geneva 1990 